\title{
Regulation of Monocarboxylate Transporter 1 in Skeletal Muscle Cells by Intracellular Signaling Pathways
}

\author{
Katsuya Narumi, Ayako Furugen, Masaki Kobayashi, Sho Otake, Shirou Itagaki, ${ }^{\dagger}$ and Ken Iseki* \\ Laboratory of Clinical Pharmaceutics \& Therapeutics, Division of Pharmasciences, Faculty of Pharmaceutical Sciences, \\ Hokkaido University; Kita 12, Nishi 6, Kita-ku, Sapporo 060-0812, Japan.
}

Received February 14, 2010; accepted June 5, 2010; published online June 14, 2010

\begin{abstract}
Skeletal muscle is the major producer of lactic acid in the body, but its oxidative fibers also use lactic acid as a respiratory fuel. Monocarboxylate transporter (MCT) 1 has been suggested to play a major role in influx of Llactic acid for oxidation. The regulation mechanism of MCT1 was characterized utilizing rhabdomyosarcoma cells as an in vitro skeletal muscle model. The uptake of L-lactic acid via MCT1 was studied in the presence of various intracellular regulatory pathways, including pathways mediated by protein kinases A, C and G (PKA, PKC and PKG), protein tyrosine kinase (PTK), and $\mathrm{Ca}^{2+} /$ calmodulin modulators. The results showed that PKG-, PTK-, and $\mathrm{Ca}^{2+} /$ calmodulin-mediated regulatory pathways play no role in the regulation of L-lactic acid uptake, but a role for PKC- and PKA-mediated pathways was apparent. Uptake of L-lactic acid appeared to be stimulated by phorbol 12-myristate 13-acetate (PMA, a PKC activator) via an increase in $V_{\max }$ of transport processes with no alteration in $K_{\mathrm{m}}$. In parallel, PMA treatment also resulted in an increase in the level of MCT1 expression. On the other hand, exposure to 8-Br-cAMP, a cAMP analog, and to forskolin, an adenylyl cyclase activator, resulted in a significant decrease in L-lactic acid uptake. Additionally, 8-Br-cAMP reduced $V_{\max }$ but not $K_{\mathrm{m}}$ values. Parallel to the decrease in $V_{\max }$ of L-lactic acid uptake, the level of MCT1 expression was decreased in response to incubation with 8-Br-cAMP. These results indicate the possible involvement of a PKC- and PKA-mediated pathway associated with expression of MCT1 and lactate transport.
\end{abstract}

Key words monocarboxylate transporter 1; skeletal muscle; L-lactic acid; protein kinase C; protein kinase A; cAMP

Skeletal muscle, which plays a crucial role in metabolism for maintenance of homeostasis, is the main producer of lactic acid in the body. Tissues such as heart and red skeletal muscle that use lactic acid as a major respiratory fuel require transportation of lactic acid into cells. Lactic acid produced by the anaerobic glycolytic pathway in skeletal muscle can be metabolized in the muscle itself. However, over-accumulation of lactic acid has been shown to lead to intracellular acidification and apoptosis. ${ }^{1)}$ Rapid transport of lactic acid across the plasma membrane is of fundamental importance for the metabolism of almost all cells, and it is also vital for intracellular $\mathrm{pH}$ homeostasis. Transport of lactate, or more accurately lactic acid, across the plasma membrane of almost all cells is catalyzed by proton-linked monocarboxylate transporters (MCTs).

The MCT family comprises 14 known members, of which the first four (MCT1-MCT4) subtypes have been demonstrated experimentally to catalyze the proton-linked transport of metabolically important monocarboxylates such as L-lactic acid. $^{2)}$ Distinct kinetic properties for L-lactic acid and pyruvate have been shown for MCT1, 2 and 4, all of which are expressed in skeletal muscle. ${ }^{3-8)}$ MCT1 is thought to play an important role in the regulation of L-lactic acid circulation into and out of muscle and the maintenance of homeostasis of skeletal muscle cells. MCT1 has been found in all fiber types in muscle tissue, but it is more abundant in muscles that have a high percentage of oxidative fibers than in glycolytic fibers and thus has been suggested to play a major role in influx of L-lactic acid for oxidation. ${ }^{9,10)}$ In rat skeletal muscle, MCT1 expression is highly correlated with indexes of oxidative metabolism, whereas MCT4 expression is highly

${ }^{\dagger}$ Present address: Department of Pharmacy, Hirosaki University School of Medicine \& Hospital; Hirosaki 036-0563, Japan. associated with indexes of muscle glycolytic metabolism. ${ }^{11)}$ MCT1 is ubiquitously expressed but is especially prominent in heart and red muscle, where it is up-regulated in response to increased work, suggesting a special role in lactic acid oxidation. We previously reported that MCT1 was responsible for L-lactic acid uptake and that L-lactic acid efflux was mediated by MCT4 in rhabdomyosarcoma (RD) and L6 skeletal muscle cells. ${ }^{12-14)}$ Thus, clarification of the control mechanism of MCT-related lactate transport will provide insights into the physiological homeostasis of skeletal muscle. The major aim of the present study was to elucidate the intracellular regulation of lactic acid uptake and MCT1 expression. Previous studies in our laboratory have demonstrated that the RD cell line can function as a suitable model to study L-lactic acid transport and have suggested that MCT1 acts on L-lactic acid uptake at RD cells as well as the skeletal muscle. ${ }^{13)}$ In this study, we investigated the roles of intracellular regulatory pathways in the regulation of MCT1, the main lactate transporter, in RD cells.

\section{MATERIALS AND METHODS}

Chemicals $\left[{ }^{14} \mathrm{C}\right]$ L-Lactic acid sodium salt was purchased from Amersham Life Science (Buckinghamshire, U.K.). L-Lactic acid sodium salt was purchased from ICN Biomedicals Inc. (Aurora, OH, U.S.A.). Genistein and bisindolylmaleimide (BIM) were obtained from Funakoshi (Tokyo, Japan). All other chemicals were obtained from SIGMA (St. Louis, MO, U.S.A.). These agents were dissolved in dimethyl sulfoxide (DMSO) and stored at $-20^{\circ} \mathrm{C}$. They were added to the incubation medium just before use.

Cell Culture Experiments were carried out using cultured human rhabdomyosarcoma cells (RD cells). RD cells of the spindle-cell type were obtained from the Japanese Col- 
lection of Research Bioresources (Osaka, Japan). RD cells, prototypic embryonal rhabdomyosarcoma cells, are tumor cells of skeletal muscle origin affecting children and young adults, and that express a number of muscle-specific proteins. ${ }^{15)} \mathrm{RD}$ cells were maintained in plastic culture flasks as described previously. ${ }^{13)}$ The RD cells were kept in Dulbecco's modified Eagle's medium with $10 \%$ fetal bovine serum (ICN Biomedicals, Inc., Aurora, OH, U.S.A.) and 1\% penicillin-streptomycin at $37^{\circ} \mathrm{C}$ under $5 \% \mathrm{CO}_{2}$.

Quantitative Real-Time Polymerase Chain Reaction (PCR) Quantitative real-time PCR was performed as described previously. ${ }^{13)}$ Quantitative real-time PCR was performed using an ABI PRISM 7700 sequence detector (Applied Biosystems, Foster City, CA, U.S.A.) with $2 \times$ SYBR Green PCR Master Mix (Invitrogen, Carlsbad, CA, U.S.A.) as per the manufacturer's protocol. Total RNA was prepared from RD cells using an RNeasy mini Kit and an RNase-Free DNase Set (QIAGEN, Tokyo, Japan). Single-strand cDNA was made from $0.5-1 \mu \mathrm{g}$ total RNA by reverse transcription (RT) using an Omniscript RT Kit. PCR was performed using MCT1- or 18S-specific primers through 40 cycles of $95^{\circ} \mathrm{C}$ for $20 \mathrm{~s}, 51^{\circ} \mathrm{C}$ for $20 \mathrm{~s}$, and $72{ }^{\circ} \mathrm{C}$ for $20 \mathrm{~s}$ after pre-incubation at $95^{\circ} \mathrm{C}$ for $15 \mathrm{~min}$. The primers specific to human MCT1 and 18S were designed on the basis of sequences in the GenBank ${ }^{\mathrm{TM}}$ database. The sequences of the specific primers were as follows: the sense sequence was $5^{\prime}$-CCA TTG TGG AAT GCT GTC CT-3' and the antisense sequence was 5'-CCA CAT GCC CAG TAT GTG TA-3' for human MCT1, and the sense sequence was 5'-CGG CTA CCA CAT CCA AGG AA-3' and the antisense sequence was 5'-GCT GGA ATT ACC GCG GCT-3' for human 18S.

Western Blot Analysis Western blot analysis was performed as described previously. ${ }^{14)}$ Total protein extracts were prepared from RD cells. The cells were scraped and centrifuged at $1300 \mathrm{~g}$ for $1 \mathrm{~min}$ at $4^{\circ} \mathrm{C}$. The pellet was suspended in $1 \mathrm{ml}$ of phosphate buffered saline (PBS) and centrifuged at $1300 \mathrm{~g}$ for $1 \mathrm{~min}$ at $4{ }^{\circ} \mathrm{C}$. The resulting pellet was suspended in a lysis buffer containing $1 \%$ Triton X-100, $0.1 \%$ sodium dodecyl sulfate (SDS) and $4.5 \mathrm{~m}$ urea. The suspension was allowed to stand for 5 min and was sonicated for $15 \mathrm{~min}$ at $4{ }^{\circ} \mathrm{C}$. The suspension was then centrifuged at $12000 \mathrm{~g}$ for $15 \mathrm{~min}$ at $4{ }^{\circ} \mathrm{C}$, and the protein concentration in the clear supernatant was determined by the method of Lowry. ${ }^{16)}$ The samples were denatured at $100{ }^{\circ} \mathrm{C}$ for $3 \mathrm{~min}$ in a loading buffer containing $50 \mathrm{~mm}$ Tris- $\mathrm{HCl}, 2 \% \mathrm{SDS}, 5 \% 2-$ mercaptoethanol, $10 \%$ glycerol, $0.002 \%$ bromophenol blue (BPB) and $3.6 \mathrm{M}$ urea and separated on $4.5 \%$ stacking and $10 \%$ SDS polyacrylamide gels. Proteins were transferred electrophoretically onto nitrocellulose membranes (TransBlot; BIO-RAD Laboratories, Richmond, CA, U.S.A.) at $15 \mathrm{~V}$ for $90 \mathrm{~min}$. The membranes were blocked with PBS containing $0.05 \%$ Tween $20(\mathrm{PBS} / \mathrm{T})$ and $10 \%$ non-fat dry milk for $1 \mathrm{~h}$ at room temperature. After being washed with $\mathrm{PBS} / \mathrm{T}$, the membranes were incubated with goat anti-MCT1 polyclonal antibody (Santa Cruz Biotechnology, Santa Cruz, CA, U.S.A.) (diluted $1: 100)$ or mouse anti-actin monoclonal antibody (Chemicon, Temecula, CA, U.S.A.) (diluted $1: 500$ ) for $24 \mathrm{~h}$ at room temperature and washed three times with $\mathrm{PBS} / \mathrm{T}$ for $10 \mathrm{~min}$ each time. The membranes were subsequently incubated for $1 \mathrm{~h}$ at room temperature with horseradish peroxidase-conjugated donkey anti-goat or goat anti- mouse secondary antibody (Santa Cruz Biotechnology, Santa Cruz, CA, U.S.A.) at a dilution of $1: 4000$ and washed three times with PBS/T for $10 \mathrm{~min}$ each time. The bands were visualized by enhanced chemiluminescence according to the instructions of the manufacturer's (Amersham Biosciences Corp., Piscataway, NJ, U.S.A.).

Uptake Study Uptake of $\left[{ }^{14} \mathrm{C}\right]$ L-lactic acid was performed as described previously. ${ }^{12}$ After removal of the growth medium, cells were washed with $\mathrm{N}$-(2-hydroxyethyl)piperazine- $N^{\prime}$-2-ethanesulfonic acid (HEPES) (pH 7.4) buffer (25 mM D-glucose, $137 \mathrm{~mm} \mathrm{NaCl}, 5.37 \mathrm{~mm} \mathrm{KCl}$, $0.3 \mathrm{~mm} \quad \mathrm{Na}_{2} \mathrm{HPO}_{4}, 0.44 \mathrm{~mm} \quad \mathrm{KH}_{2} \mathrm{PO}_{4}, 4.17 \mathrm{~mm} \mathrm{NaHCO}$, $1.26 \mathrm{~mm} \mathrm{CaCl}_{2}, 0.8 \mathrm{~mm} \mathrm{MgSO}_{4}$ and $10 \mathrm{~mm}$ HEPES) and preincubated at $37^{\circ} \mathrm{C}$ for $10 \mathrm{~min}$ with $0.5 \mathrm{ml}$ of HEPES $(\mathrm{pH}$ 7.4) buffer. Uptake was initiated by applying $2-(N$-morpholino)ethanesulfonic acid (MES) ( $\mathrm{pH}$ 6.0) buffer $(25 \mathrm{~mm}$ D-glucose, $137 \mathrm{~mm} \mathrm{NaCl}, 5.37 \mathrm{~mm} \mathrm{KCl}, 0.3 \mathrm{~mm} \mathrm{Na}_{2} \mathrm{HPO}_{4}$, $0.44 \mathrm{~mm} \mathrm{KH}_{2} \mathrm{PO}_{4}, 4.17 \mathrm{~mm} \mathrm{NaHCO}, 1.26 \mathrm{~mm} \mathrm{CaCl}_{2}, 0.8 \mathrm{~mm}$ $\mathrm{MgSO}_{4}$ and $10 \mathrm{~mm}$ MES) or HEPES (pH 7.4) buffer containing $\left[{ }^{14} \mathrm{C}\right]$ L-lactic acid $(0.2 \mu \mathrm{Ci} / \mathrm{ml})$. The uptake study was performed at $37^{\circ} \mathrm{C}$. After a predetermined time period, uptake was terminated by suctioning off the applied solution and immersing the plates in ice-cold HEPES (pH 7.4) buffer. To quantify the radioactivity of $\left[{ }^{14} \mathrm{C}\right]$ L-lactic acid taken up by the cells, the cells were solubilized in $1 \% \mathrm{SDS} / 0.2 \mathrm{~N}$ $\mathrm{NaOH}$. The remainder of the sample was mixed with $5 \mathrm{ml}$ of scintillation cocktail (ASCII, Amersham Biosciences Corp., Piscataway, NJ, U.S.A.) to measure the radioactivity in a liquid scintillation counter (Packard, 1600TR). The cellular protein content was determined by the method of Lowry with bovine serum albumin as a standard. ${ }^{16)}$

Reporter Plasmid Construction The human MCT1 promoter (-1538/+218; Accession No. NM_003051) was amplified from human genomic DNA by PCR using primers with the sense sequence of 5'-TTT CTC GAG GAA CCA GAC TGA GGA TCC TGT C-3' and antisense sequence of 5'-CGC AAG CTT CCT CGT TTG CTT GTT CCA GT-3' and then subcloned into a pGL3-basic vector (Promega, Madison, WI, U.S.A.) that contains a promoterless luciferase reporter gene.

Transient Transfection and Luciferase Assay RD cells $\left(1.5 \times 10^{5}\right.$ cells/well $)$ were seeded into 24 -well plates and transfected while still in suspension with one of the MCT1 promoter-luciferase constructs using Lipofectin reagent (Invitrogen, Carlsbad, CA, U.S.A.). Each well was transfected with $400 \mathrm{ng}$ of pGL3-MCT4 promoter construct encoding a modified firefly luciferase gene (or empty pGL3 vector). After transfection, cells were treated with phorbol 12-myristate 13 -acetate (PMA) or 8-Br-cAMP for 1,6 , or $24 \mathrm{~h}$. At $48 \mathrm{~h}$ after transfection, luciferase activity measured by a luminometer according to the manufacturer's instructions using an assay kit from Promega. Relative light unit (RLU) values obtained from the assay were normalized to the amount of protein used as determined by the Lowry method ${ }^{16)}$ and luciferase activity was expressed as RLU/mg protein.

Data Analysis For kinetic studies, the MichaelisMenten constant $\left(K_{\mathrm{m}}\right)$ and maximum uptake rate $\left(V_{\max }\right)$ of Llactic acid were estimated from the following equation using a nonlinear least-squares regression analysis:

$$
v=V_{\max } \cdot S / K_{\mathrm{m}}+S
$$


where $V$ and $S$ are uptake rate of L-lactic acid and concentration of L-lactic acid, respectively.

Unless otherwise indicated, all data are expressed as means \pm S.D. of the mean. Student's $t$-test was used to determine the significance of differences between two group means. Statistical significance was defined as $p<0.05$.

\section{RESULTS}

Cellular Regulation of L-Lactic Acid Uptake by RD Cells Firstly, to clarify the role of intracellular regulatory pathways in the regulation of L-lactic acid uptake, we examined the effects of various modulators on L-lactic acid uptake by RD cells. The uptake of L-lactic acid was studied in the presence of various intracellular regulatory pathways, including pathways mediated by protein kinases $\mathrm{A}, \mathrm{C}$ and $\mathrm{G}$ (PKA, PKC and PKG), protein tyrosine kinase (PTK), and $\mathrm{Ca}^{2+}$ calmodulin modulators. As shown in Table 1, incubation with $10 \mu \mathrm{M}$ PMA, a well-known PKC activator, for $24 \mathrm{~h}$ significantly increased the uptake of L-lactic acid. Moreover, incubation of RD cells with a membrane-permeant cAMP ana-

Table 1. Effects of Various Modulators on L-Lactic Acid Uptake in RD Cells

\begin{tabular}{lcc}
\hline \hline Modulators & $\begin{array}{c}\text { Concentration } \\
(\mu \mathrm{M})\end{array}$ & $\begin{array}{c}\left.{ }^{14} \mathrm{C}\right] \text { L-Lactate uptake } \\
(\% \text { of control })\end{array}$ \\
\hline PMA & 0.1 & $105.57 \pm 7.63$ \\
& 1 & $105.98 \pm 2.48$ \\
8-Br-cAMP & 10 & $135.54 \pm 11.14^{*}$ \\
Forskolin & 250 & $82.92 \pm 3.05^{* *}$ \\
Calmidazolium & 500 & $60.01 \pm 5.28^{*} *$ \\
pCPT-cGMP & 10 & $77.25 \pm 1.72^{*} *$ \\
& 100 & $83.72 \pm 7.11^{*} *$ \\
Genistein & 0.1 & $99.49 \pm 6.92$ \\
& 1 & $85.53 \pm 2.73^{*}$ \\
& 5 & $105.54 \pm 3.28$ \\
& 50 & $102.23 \pm 3.66$ \\
& 50 & $105.71 \pm 7.31$ \\
& 50 & $107.63 \pm 10.15$
\end{tabular}

Post-confluent RD cells were treated with modulators (PMA, 8-Br-cAMP, forskolin, calmidazolium, pCPT-cGMP and genistein) for $24 \mathrm{~h}$. $\left[{ }^{14} \mathrm{C}\right]$ L-Lactic acid uptake by RD cells was measured at $\mathrm{pH} 6.0$ for $5 \mathrm{~min}$. Each value represents the mean \pm S.D. of three to four separate uptake determinations. $* p<0.05$, $* * p<0.01$, significantly different from the control. $\log$, 8-Br-cAMP, or an adenylyl cyclase activator, forskolin, for $24 \mathrm{~h}$ resulted in a significant decrease in L-lactic acid uptake. On the other hand, no significant change in L-lactic acid uptake was found upon treatment of RD cells with 8-(4chlorophenylthio)-cGMP (pCPT-cGMP), a membrane-permeable analog of cGMP. Similarly, neither genistein, a PTK inhibitor, nor calmidazolium, a calmodulin inhibitor, exhibited a significant effect. These results indicate that while no role for PKG-, PTK- and $\mathrm{Ca}^{2+} /$ calmodulin-mediated pathways is evident, there appears to be a role for the PKC- and PKA-mediated pathways.

Involvement of PKC- and PKA-Mediated Pathways in MCT1 Expression and Function in RD Cells Previous studies from our laboratory have suggested that MCT1 is responsible for L-lactic acid uptake in RD cells. ${ }^{13)}$ Next, to clarify the potential role of PKC- and PKA-mediated pathways in the regulation of L-lactic acid uptake, we examined the effects of PMA and 8-Br-cAMP on the expression of MCT1 in RD cells. As shown in Fig. 1a, the level of MCT1 mRNA was significantly increased by 1.5 fold in RD cells treated for $24 \mathrm{~h}$ with PMA $(10 \mu \mathrm{M})$ compared with the control level. We also investigated whether alteration in MCT1 mRNA expression correlated with the protein expression. Figure $1 \mathrm{~b}$ shows a representative Western blot indicating the expected size bands of both human MCT1 (45 kDa) and actin ( $42 \mathrm{kDa})$ utilizing specific antibodies and protein lysates from RD cells treated with PMA. The level of MCT1 protein was significantly increased in RD cells treated for $24 \mathrm{~h}$ with PMA. Moreover, BIM, a PKC inhibitor, significantly inhibited MCT1 mRNA elevation induced by PMA (Fig. 1c). In contrast, the level of MCT1 mRNA was significantly decreased in $\mathrm{RD}$ cells treated for $24 \mathrm{~h}$ with 8 -Br-cAMP in a concentration dependent manner (Fig. 2a). Moreover, MCT1 protein level was significantly decreased in RD cells treated for $24 \mathrm{~h}$ with 8-Br-cAMP in parallel to MCT1 mRNA alteration (Fig. $2 b)$. We further assessed the influence of PKA-mediated pathways on L-lactic acid uptake via MCT1 in RD cells. As shown in Fig. 2c, the suppressive effect of 8-Br-cAMP on Llactic acid uptake was abolished by H89, a specific PKA inhibitor.

Effects of PMA and 8-Br-cAMP on the Kinetics of $\mathrm{L}_{-}$ Lactic Acid Uptake in RD Cells Finally, we examined the effects of PMA and 8-Br-cAMP on MCT1 function and the (a)

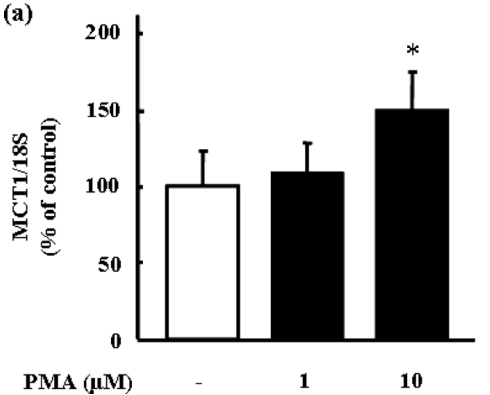

(b)

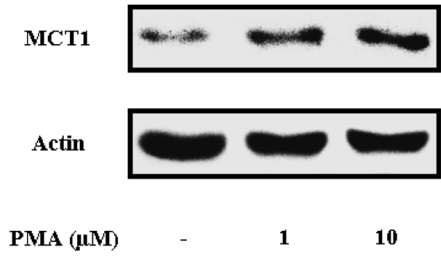

(c)

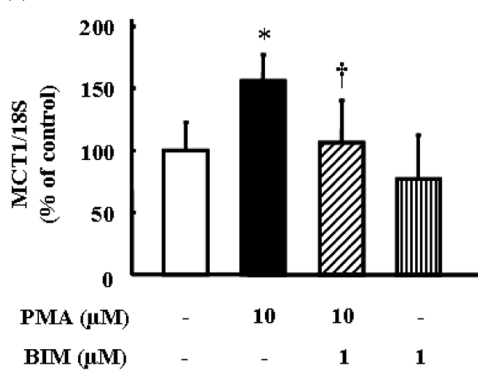

Fig. 1. Effects of PKC Pathway Modulators on MCT1 Expression in RD Cells

(a) RD cells were exposed to PMA $(1,10 \mu \mathrm{M})$ for $24 \mathrm{~h}$. Total RNA isolated from the cells was reverse transcribed into cDNA and subjected to PCR using MCT1-specific primers. MCT1 mRNA levels were determined using quantitative real-time reverse transcription-PCR. Data are expressed as relative ribosomal 18S RNA in the same samples. Each column represents the mean with S.D. of four to six separate determinations. * Significantly different from no addition at $p<0.05$. (b) RD cells were exposed to PMA (1, $10 \mu \mathrm{M}$ ) for $24 \mathrm{~h}$. Whole cell extracts were prepared from the cells and resolved using SDS-PAGE. Western blotting was carried out with antibodies to MCT1 or $\beta$-actin. Two separate experiments gave similar results. (c) RD cells were exposed to PMA in the absence or presence of BIM for $24 \mathrm{~h}$. MCT1 mRNA levels were determined using quantitative real-time reverse transcription-PCR as described above. Each column represents the mean with S.D. of four to six separate determinations. $*$ Significantly different from no addition at $p<0.05, \uparrow$ Significantly different from $10 \mu \mathrm{M}$ PMA alone at $p<0.05$. 
(a)

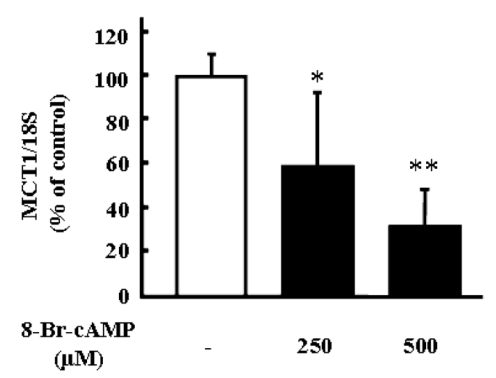

(b)

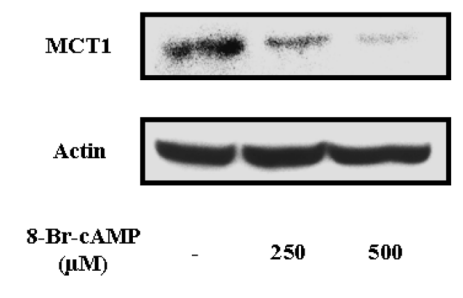

(c)

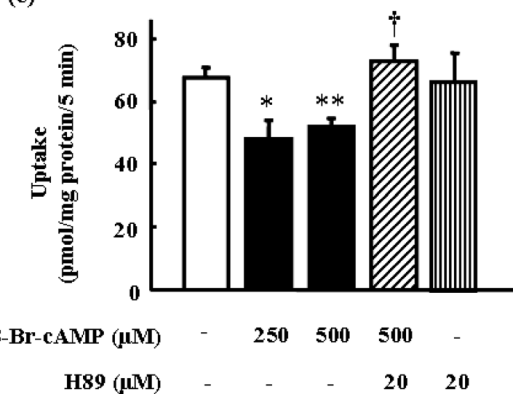

Fig. 2. Effects of PKA Pathway Modulators on MCT1 Expression ((a), (b)) and L-Lactic Acid Uptake (c) in RD Cells

(a) RD cells were exposed to 8 -Br-cAMP $(250,500 \mu \mathrm{M})$ for $24 \mathrm{~h}$. MCT1 mRNA levels were determined using quantitative real-time reverse transcription-PCR as described above. Each column represents the mean with S.D. of four to six separate determinations. $*, * *$ Significantly different from no addition at $p<0.05, p<0.01$. (b) RD cells were exposed to 8 -Br-cAMP $(250,500 \mu \mathrm{M})$ for $24 \mathrm{~h}$. Western blotting was carried out with antibodies to MCT1 or $\beta$-actin as described above. Two separate experiments gave similar results. (c) RD cells were exposed to 8-Br-cAMP in the absence or presence of H89 for $24 \mathrm{~h}$. Each column represents the mean with S.D. of four separate uptake determinations. $*, * *$ Significantly different from no addition at $p<0.05,<0.01, \uparrow$ Significantly different from $500 \mu \mathrm{M} 8$-Br-cAMP alone at $p<0.05$.

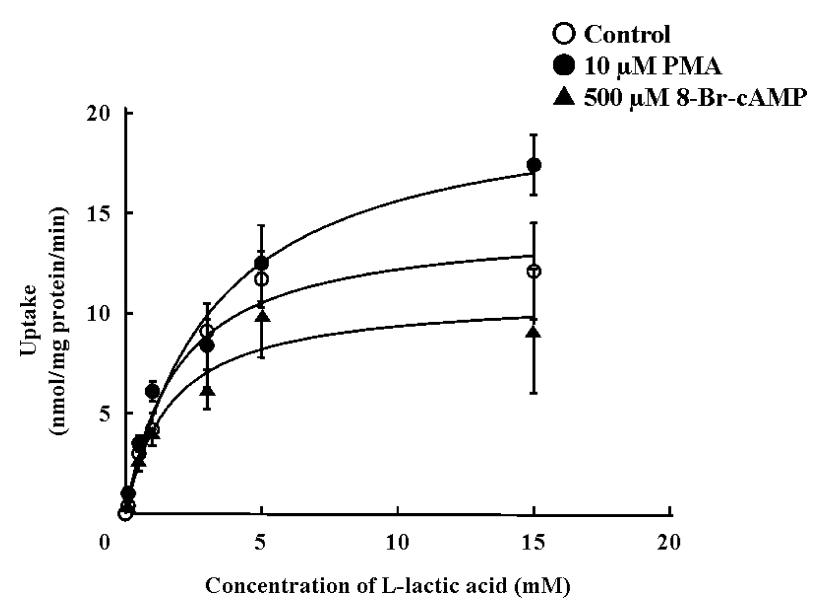

Fig. 3. Effects of PMA and 8-Br-cAMP on Concentration Dependence of L-Lactic Acid Uptake in RD Cells

RD cells were exposed to PMA $(10 \mu \mathrm{M})$ or 8 -Br-cAMP $(500 \mu \mathrm{M})$ for $24 \mathrm{~h}$. $\left[{ }^{14} \mathrm{C}\right] \mathrm{L}-$ Lactic acid uptake by RD cells was measured at $\mathrm{pH} 6.0$ for $5 \mathrm{~min}$. Each point represents the mean \pm S.D. of three to nine separate uptake determinations.

concentration dependence of L-lactic acid uptake in RD cells. As shown in Fig. 3, 24-h incubation with $10 \mu \mathrm{M}$ PMA caused a $40 \%$ increase in $V_{\max }$ of the transport process compared with the control $(14.5 \pm 1.0$ and $20.7 \pm 1.8 \mathrm{nmol} / \mathrm{mg}$ protein/ min for control and PMA-treated cells, respectively), whereas the $K_{\mathrm{m}}$ values were not significantly changed. On the other hand, kinetic analysis revealed that the 8-Br-cAMP-induced decrease in L-lactic acid uptake was accompanied by change in $V_{\max }$. Exposure to 8-Br-cAMP for $24 \mathrm{~h}$ decreased $V_{\max }$ from $14.5 \pm 1.0$ to $10.9 \pm 1.8 \mathrm{nmol} / \mathrm{mg}$ protein $/ \mathrm{min}$ in 8 Br-cAMP-treated RD cells.

\section{DISCUSSION}

Skeletal muscle, which plays a crucial role in metabolism for maintenance of homeostasis, is the main producer of lactic acid in the body. Lactic acid is an important metabolic intermediate that plays a major role in the homeostatic control of skeletal muscles. Various studies have suggested roles of intracellular signaling pathways in MCT1 regulation. Although many studies have focused on the regulation of MCT1 expression in various cell lines derived from humans, little is known about its regulation mechanism in skeletal muscle. The present study was undertaken to investigate the possible regulation of MCT1 by the major signaling pathways, namely protein kinase A, C and G (PKA, PKC and $\mathrm{PKG})$, protein tyrosine kinase (PTK), $\mathrm{Ca}^{2+} /$ calmodulin-mediated pathways. First, we examined the effects of various modulators on L-lactic acid uptake by RD cells. Our data showed that the PKG-, PTK-, $\mathrm{Ca}^{2+} /$ calmodulin-mediated regulatory pathways play no role in the regulation of L-lactic acid uptake and suggested that these pathways have no role in MCT1 regulation (Table 1). On the other hand, PMA, a PKC activator, significantly increased the uptake of L-lactic acid in RD cells. Similarly, exposure to PMA for $24 \mathrm{~h}$ significantly increased MCT1 mRNA and protein levels. This stimulation of the uptake of L-lactic acid by PMA appears to be via an increase in $V_{\max }$ of the transport process with no alteration in $K_{\mathrm{m}}$. This indicated that PMA stimulated L-lactic acid uptake by increased abundance of MCT1 proteins. Moreover, BIM, a PKC inhibitor, significantly inhibited MCT1 mRNA elevation induced by PMA. These results suggest that PKCmediated MCT1 expression in RD cells is a straightforward process, with increased transcription followed by increased abundance of MCT1 proteins and stimulation of L-lactate uptake. In contrast, exposure to 8-Br-cAMP and forskolin for $24 \mathrm{~h}$ resulted in a significant decrease in L-lactic acid uptake. The reduction of L-lactic acid uptake by cAMP modulators suggests a role of cAMP-mediated PKA pathways in the regulation of L-lactic acid transport activity or MCT1 expression. Additionally, exposure to 8 -Br-cAMP for $24 \mathrm{~h}$ significantly decreased the MCT1 mRNA level as well as the MCT1 protein level in RD cells. These results suggest the involvement of a cAMP-mediated PKA pathway in the regulation of L-lactic acid uptake via MCT1 in RD cells. However, the protein expression profile of MCT1 in Fig. 2b is not consistent with the reduction of L-lactic acid transport activity by 8 -Br-cAMP shown in Table 1 . We previously reported that MCT1, MCT2 and MCT4 mRNA was detected in RD cells. Additionally, it has been suggested that MCT1 rather than MCT2 is mainly responsible for L-lactic acid uptake by RD cells. ${ }^{13)}$ Therefore, not only MCT1 but also another transporter may contribute to the transport of L-lactic acid in RD cells. Moreover, to determine whether the suppressive effect of 8-Br-cAMP on L-lactic acid uptake is attributed specifically to PKA activation, we examined the effect of H89, a specific PKA inhibitor on the inhibition of L-lactic acid up- 
take by 8 -Br-cAMP. The inhibitory effect of 8 -Br-cAMP was abolished by H89. These results suggest the involvement of a cAMP-mediated PKA pathway in the regulation of L-lactic acid uptake in RD cells.

The results of the present study showed the long-term effects of PMA and 8-Br-cAMP. Another study has shown that PMA treatment (for $24 \mathrm{~h}$ ) significantly increased apical butyrate uptake and MCT1 protein expression in Caco-2 cells. ${ }^{17)}$ Recent studies have also shown that intestinal MCT1 gene expression in response to PMA is attributed to initial $\mathrm{PKC}$ activation and that the atypical $\mathrm{PKC}-\zeta$ isoform plays a role in PMA-induced up-regulation of the MCT1 promoter. ${ }^{18)}$ Therefore, we also examined whether the effect of PMA on MCT1 promoter activity is due to initial PKC activation in RD cells. RD cells were treated with PMA at various time points ranging from 1 to $24 \mathrm{~h}$. PMA-induced MCT1 promoter activity was seen as early as $1 \mathrm{~h}$ and persisted until the 24-h time point (data not shown). These results are consistent with the results of a previous study showing that exposure to PMA for a long period stimulated MCT1 expression. Thus, these results demonstrate that the stimulatory effects of PMA on MCT1 expression were attributed to initial PKC activation not only in Caco-2 cells but also in RD cells. On the other hand, a significant decrease in MCT1 promoter activity was seen when the cells were incubated for $24 \mathrm{~h}$, but not for $1 \mathrm{~h}$ or $6 \mathrm{~h}$, with 8 -Br-cAMP (data not shown). These results suggest that 8-Br-cAMP has no effect on the direct modification of MCT1 and that the decrease in MCT1 expression seen in this study could be a secondary effect following the intracellular accumulation of cAMP.

Various protein kinase systems have been shown to affect protein modification. Activation of PKA or PKC has been associated with alterations of transporter function and the presence of transporters in the plasma membrane. Recent studies have also shown rapid modulation of transporters by PKA and PKC. ${ }^{19,20)}$ In rat cerebral endothelial cells, MCT1 kinetic function is directly modulated by a cAMP-mediated PKA signaling pathway. ${ }^{21)}$ However, little is known about the short-term effects of protein kinase modulators on MCT1. We tried to clarify the possible regulation of MCT1 by shortterm exposure (within $1 \mathrm{~h}$ ) to PMA or 8-Br-cAMP. One-hour incubation with $10 \mu \mathrm{M}$ PMA exhibited no effect on the uptake of L-lactic acid in RD cells (data not shown). Similarly, no significant change in L-lactic acid uptake was found upon treatment with 8-Br-cAMP (data not shown). These results suggest that PMA and 8-Br-cAMP have no effect on direct modification of MCT1 such as phosphorylation or recruitment to the plasma membrane in RD cells. PKC and PKA are found in almost all cell types as effectors of various signal transduction pathways and play a central role in physiological homeostasis. Therefore, it is likely that different isozymes with distinct biochemical properties and cell-specific expression contribute to cell- and organ-specific effects.

MCT1 expression in skeletal muscles is increased in response to chronic stimulation and endurance exercise training in rats and humans, whereas muscle denervation decreases expression of MCT1. ${ }^{10,11,22)}$ However, the mechanism of regulation has not been established. Muscle contraction has been shown to increase PKC activity. ${ }^{23)}$ Additionally, there is information indicating that muscle denervation causes intracellular accumulation of cAMP and stimulates
PKA activity in muscle. ${ }^{24}$ In this report, we indicated the possible involvement of a PKC and cAMP-mediated PKA pathway associated with expression of MCT1. Our results together with the above-mentioned observations support the view that $\mathrm{PKC}$ is an important signaling molecule activated by muscle contraction and is involved in the regulation of contraction-stimulated MCT1 expression. Furthermore, our results suggest that cAMP plays an important role in the regulation of MCT1 expression after denervation. Most signal transduction pathways are involved in various cellular functions. However, the physiological significance of the multiple-signal regulating pathways involved in the regulation of MCT1 in skeletal muscle is poorly understood and needs to be further explored.

In conclusion, the results of present study indicate the possible involvement of a PKC- and PKA-mediated pathway associated with expression of MCT1 and lactate transport. Our results provide evidence for a link between the regulation of MCT1 expression and signaling molecules central to the control of homeostasis of skeletal muscle cells, but the detailed downstream pathway of this signaling cascade involved in the regulation of MCT1 expression remains to be elucidated. Further investigations to elucidate this pathway are in progress.

\section{REFERENCES}

1) Jeong D., Kim T. S., Lee J. W., Kim K. T., Kim H. J., Kim I. H., Kim I. Y., Biochem. Biophys. Res. Commun., 289, 1141-1149 (2001).

2) Halestrap A. P., Meredith D., Pflugers Arch., 447, 619-628 (2004).

3) Broer S., Broer A., Schneider H. P., Stegen C., Halestrap A. P., Deitmer J. W., Biochem. J., 341, 529-535 (1999).

4) Broer S., Schneider H. P., Broer A., Rahman B., Hamprecht B., Deitmer J. W., Biochem. J., 333, 167-174 (1998).

5) Dimmer K. S., Friedrich B., Lang F., Deitmer J. W., Broer S., Biochem. J., 350, 219-227 (2000).

6) Bonen A., Miskovic D., Tonouchi M., Lemieux K., Wilson M. C., Marette A., Halestrap A. P., Am. J. Physiol. Endocrinol. Metab., 278, 1067-1077 (2000)

7) Benton C. R., Campbell S. E., Tonouchi M., Hatta H., Bonen A., Biochem. Biophys. Res. Commun., 323, 249-253 (2004).

8) Bonen A., Heynen M., Hatta H., Appl. Physiol. Nutr. Metab., 31, 3139 (2006).

9) Pilegaard H., Terzis G., Halestrap A. P., Juel C., Am. J. Physiol., 276, 843-848 (1999).

10) Juel C., Halestrap A. P., J. Physiol., 517, 633-642 (1999).

11) Wilson M. C., Jackson V. N., Hedle C., Price N. T., Pilegaard H., Juel C., Bonen A., Montgomery I., Hutter O. F., Halestrap A. P., J. Biol. Chem., 273, 15920-15926 (1998).

12) Kobayashi M., Itagaki S., Hirano T., Iseki K., Drug Metab. Pharmacokinet., 19, 363-368 (2004).

13) Kobayashi M., Fujita I., Itagaki S., Hirano T., Iseki K., Biol. Pharm. Bull., 28, 1197-1201 (2005).

14) Kobayashi M., Otsuka Y., Itagaki S., Hirano T., Iseki K., Int. J. Pharm., 317, 19-25 (2006).

15) Knudsen E. S., Pazzagli C, Born T. L., Bertolaet B. L., Knudsen K. E., Arden K. C., Henry R. R., Feramisco J. R., Cancer Res., 58, 20422049 (1998).

16) Lowry O. H., Rosebrough N. J., Farr A. L., Randall R. J., J. Biol Chem., 193, 265-275 (1951).

17) Alrefai W. A., Tyagi S., Gill R., Saksena S., Hadjiagapiou C., Mansour F., Ramaswamy K., Dudeja P. K., Am. J. Physiol. Gastrointest. Liver Physiol., 286, G197-G203 (2004).

18) Saksena S., Dwivedi A., Gill R. K, Singla A., Alrefai W. A., Malakooti J., Ramaswamy K., Dudeja P. K., Am. J. Physiol. Gastrointest. Liver Physiol., 296, G275-G283 (2009).

19) Subramanian S., Glitz P., Kipp H., Kinne R. K., Castaneda F., J. Cell Biochem., 106, 444-452 (2009). 
20) Köck K., Koenen A., Giese B., Fraunholz M., May K., Siegmund W., Hammer E., Völker U., Jedlitschky G., Kroemer H. K., Grube M., J. Biol. Chem., 285, 11336-11347 (2010).

21) Smith J. P., Drewes L. R., J. Biol. Chem., 281, 2053-2060 (2006).

22) Baker S. K., McCullagh K. J., Bonen A., J. Appl. Physiol., 84, 987-
994 (1998).

23) Perrini S., Henriksson J., Zierath J. R., Widegren U., Diabetes, 53, 21-24 (2004).

24) Chahine K. G., Baracchini E., Goldman D., J. Biol. Chem., 268, 2893-2898 (1993). 